\title{
Long-term behaviour of concrete structures reinforced with pre-stressed GFRP tendons
}

\author{
J. Fornůsek ${ }^{1}$, P. Konvalinka ${ }^{1}$, R. Sovják ${ }^{1}$ \& J. L. Vítek ${ }^{2}$ \\ ${ }^{I}$ Experimental Centre, Faculty of Civil Engineering, \\ Czech Technical University in Prague, Czech Republic \\ ${ }^{2}$ Department of Masonry and Concrete Structures, \\ Faculty of Civil Engineering, Czech Technical University in Prague, \\ Czech Republic
}

\begin{abstract}
Nowadays, composite materials are used more often in every part of industry, including civil engineering. Using these composite materials in civil engineering is innovational and there are many unanswered questions about these materials and the relaxation of the glass fibre reinforced polymers (GFRP) tendon in pre-stressed concrete is one of them. Knowing the long-term behaviour of the pre-stressed GFRP tendons is very important for the right design. Underestimating the long-term changes in the GFRP tendons can lead to serious problems or collapse of a structure. This paper shows two long-term experiments. One of them is the relaxation of pre-stressed GFRP tendons and the second one is creep of a concrete slab reinforced with pre-stressed GFRP tendons. The first experiment shows that relaxation of pre-stressed GFRP tendons is very high. A GFRP tendon was pre-stressed up to $37 \%$ (237,9 MPa) of its tensile strength $(654,0 \mathrm{MPa})$. The decrease of tensile stress when the experiment was closed (after 132 days) was about 10,5\%. Based on the experimental data, the numerical viscoelastic model consisting of Kelvin links was developed. The modulus of elasticity of the fibres and matrix was determined with the nanoindentation method. Others parameters were fitted from the experimental data. The chosen numerical model corresponds very well with the experimental data, but for the best outcome a longer experiment should be carried out. The numerical model and fitting of parameters were made in MATLAB 2007a software. The creep of the slab shows the long-term behaviour of a structure reinforced with GFRP tendons. The creep test was ended after one year. A concrete slab pre-stressed with GFRP tendons was subjected to a four point loading test with a constant load. During the year deflections and strain were recorded and hence the creep curve is plotted.

Keywords: GFRP, creep, relaxation, long-term behaviour, pre-stressing.
\end{abstract}




\section{Introduction}

Composite materials are being used more frequently in all parts of industry; civil engineering is not the exception. Use of these non-traditional materials brings many questions that should be answered. No national instructions exist for designing of these structures in the Czech Republic. This vacuum leads to very low use and mistrust of this reinforcement type. Experiments are trying to fill this vacuum with new knowledge. The long-term behaviour of composite reinforcement and structures reinforced with this reinforcement is one of the most important themes for the correct design of structures. The underestimating of long-term behaviour can lead to serious problems in the future of the structures.

\section{Characteristics of composite reinforcement}

Composite reinforcement for internal reinforcing of concrete structures consists of fibres and a matrix (FRP - fibre reinforced polymers). The fibres are the main bearers of mechanical properties. Nowadays three different types of fibres are used - aramid (AFRP), carbon (CFRP) and glass (GFRP). The matrix usually consists of vinylester, epoxy or other polymers.

There are many differences between common steel reinforcement and composite reinforcement - FRP. Using FRP reinforcement has advantages and disadvantages. The most outstanding advantage is vulnerability against corrosion in an aggressive environment. The other advantages are low weight, high tensile strength and transparency for electromagnetic radiation (GFRP). These qualities can be used for structures in very aggressive environments, for example, for the restoration of structures and for antenna covers.

On the other hand there are a few disadvantages, such as the low modulus of elasticity, fragility and not least the high purchase price. The low elasticity modulus means high deflections and deformations of FRP reinforced structures. The effect of the low elasticity modulus can be reduced by pre-stressing of structures.

The diameter of the GFRP tendons was $14 \mathrm{~mm}$. There were some differences between the featured and measured modulus of elasticity.

Table 1: $\quad$ Basic characteristics of GFRP tendons.

\begin{tabular}{|c|c|c|}
\hline & $\begin{array}{l}\text { PREFA KOMPOZITY } \\
\text { a.s. }\end{array}$ & $\begin{array}{c}\text { Measurement in EC, } \\
\text { FCE }\end{array}$ \\
\hline $\begin{array}{c}\text { Modulus of elasticity } \\
{[\mathrm{GPa}]}\end{array}$ & 32,14 & 41,11 \\
\hline Tensile strength [MPa] & 654,66 & $\begin{array}{c}>600 \text { (max. load } . \\
\text { machine })\end{array}$ \\
\hline Thermal expansion $\left[\mathrm{K}^{-1}\right]$ & $5.10^{-6}$ & $7,5.10^{-6}$ \\
\hline
\end{tabular}

Glass vs. matrix ratio was $73: 27\left(\mathrm{c}_{1}=0,73 ; \mathrm{c}_{2}=0,27\right)$. 


\section{Characteristics of the GFRP tendons used}

The GFRP tendons were made by the firm PREFA KOMPOSITY, a.s., Brno, Czech Republic. The basic characteristics of the tendons are shown in table 1.

\section{Creep test of concrete slab pre-stressed with GFRP tendons}

\subsection{Properties of the concrete slab}

The concrete slab was cast in January 2008. The GFRP tendons were prestressed before casting, therefore the so called pre tensioned concrete slab was performed.

The scheme of the slab is shown in figure 1 . The dimensions of the slab were $4500 \times 600 \times 200 \mathrm{~mm}(\mathrm{~L} \times \mathrm{W} \times \mathrm{H})$. The slab was designed as the simple beam. There were two pairs (four sticks) of vibrating wire (VW) strain gages embedded in the concrete slab. The first pair was embedded in the end of the slab and the second pair was embedded in the middle of the slab. One VW strain gage of the pair was embedded on the upper side of the slab and the second on the lower side.

Pre-stressing was applied 14 days after casting. The strength of the pre-stressing force was circa $32 \mathrm{kN}$ in each tendon (which means tension circa $215 \mathrm{MPa}$ ). Three displacement sensors were placed under the slab for measuring of deflection. One of them was placed in the middle and the other under the concentrated loads.

Four cylinders were also cast as referential samples for measuring of the shrinkage and temperature effects at the same time. In each cylinder there was an embedded VW strain gage. Two of the cylinders were loaded at the same time as the slab.

\subsection{Creep experiment behaviour}

Load was applied 28 days after casting. The weight of each concentrated load (F) was $1000 \mathrm{~kg}$, which means a force of $10 \mathrm{kN}$. Regular measurement of the strain and deflection was accomplished since the load was set. The duration of the experiment was designed as one year. The time dependent graph of the strain is shown in figure 2 and the time-deflection graph of the slab is shown in figure 3. The graph of strain of the cylinders is shown in figure 4.

The deflection of the slab is going to be stabilized on the value of about $20 \mathrm{~mm}$ in the middle. After the end of this experiment the measured relaxation of the GFRP tendons and the creep of the slab should be unified into the numerical model. This model should proof if the relaxation of the GFRP tendons with the numerical creep model of concrete corresponds with the creep measurement of the slab.

\section{Relaxation of the GFRP tendon}

The long-term behaviour of the GFRP tendon has not been well inspected so far. So, the test of time dependent tension loses was set. This experiment is closely 


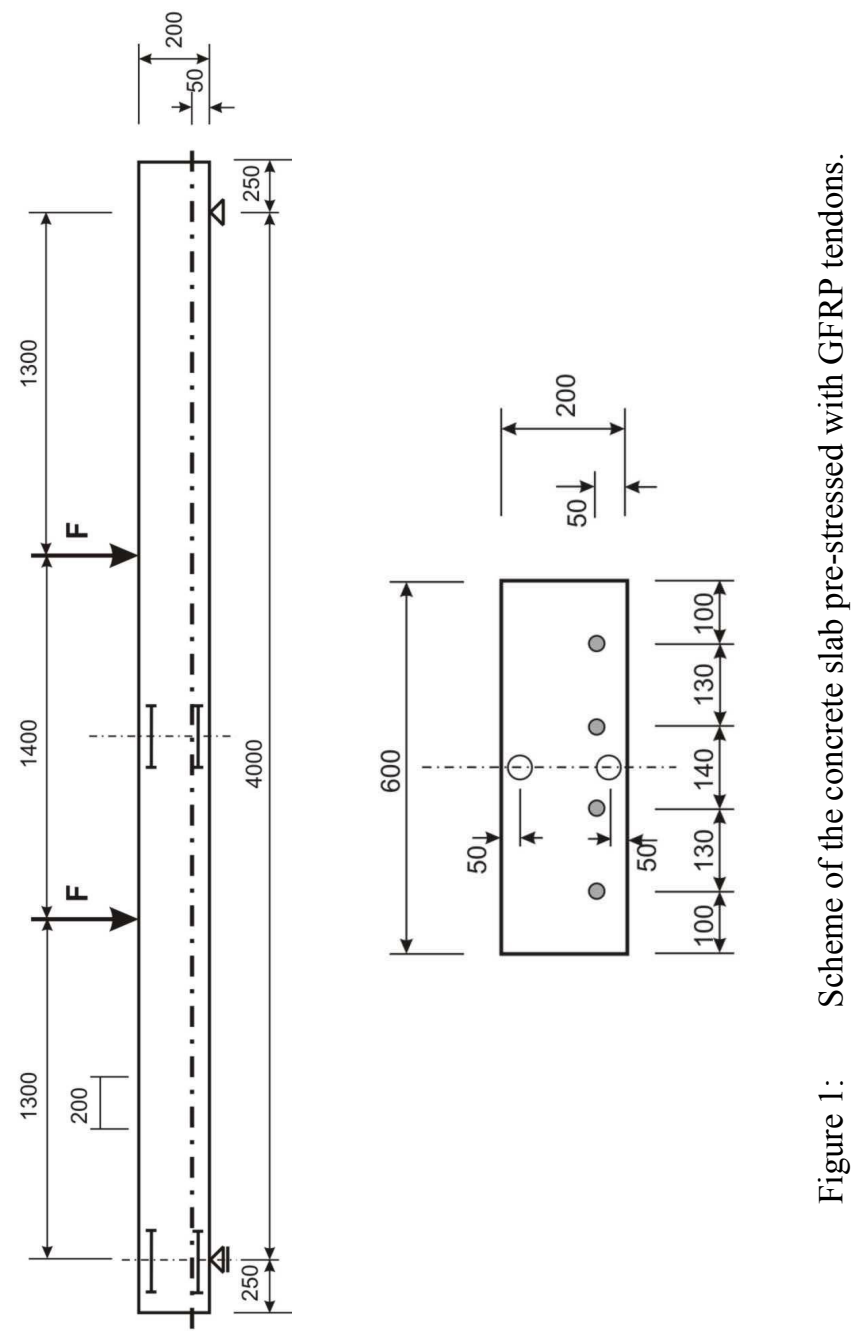


linked with the creep test. This experiment was designed for one year but it was cut after c 4 months because of insufficient space in the experimental hall.

\subsection{Stressing bed for measuring of the time dependent tension decreasing}

A special stressing bed for measuring of the relaxation in the Experimental Centre was designed. The main features of the stressing bed are to be seen in figure 6 . The construction of the stressing bed takes into account the slip of the pre-stressed GFRP tendon in the steel anchors as well as the effect of the temperature. The principle of the stressing bed is very simple. The GFRP tendon with steel anchors (on both sides) is placed into the stressing bed. One end is



Figure 2: $\quad$ Time-strain graph of the slab.

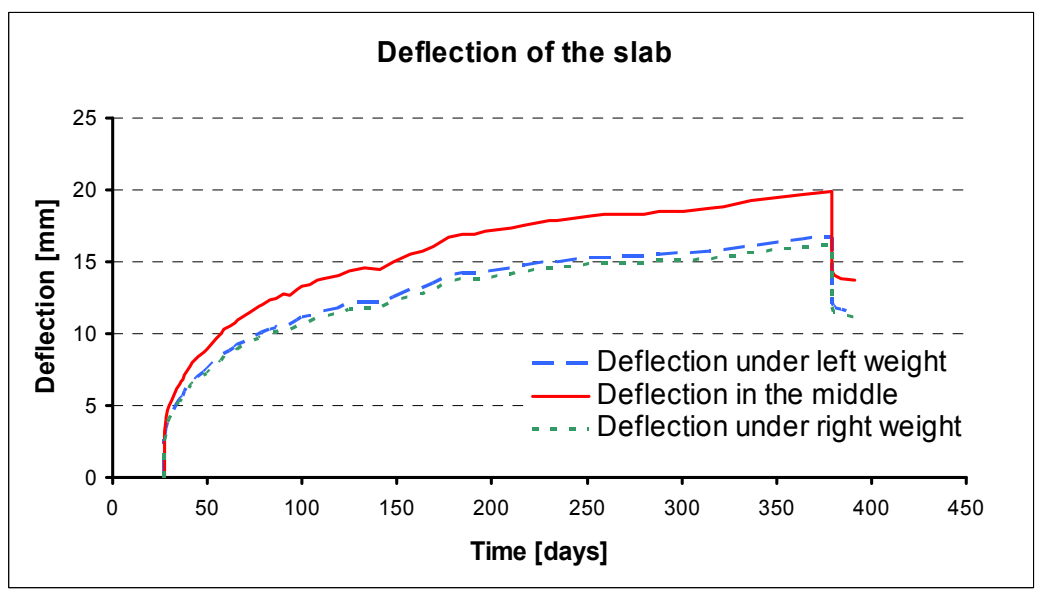

Figure 3: Time-deflection graph of the slab. 
placed on the two load cells and the second end is placed in the movable part. The movable part is joined to the fixed profile with a screwed bar. The pre-stressing is brought in with the nut rotation on the screwed bar.

\subsection{Experimental behaviour (relaxation test)}

The $5400 \mathrm{~mm}$ long GFRP tendon was pre-stressed in the stressing bed to $37 \%$ $(239,7 \mathrm{MPa})$ of its tensile strength $(654,7 \mathrm{MPa})$. This means that the force is about $36,6 \mathrm{kN}$. Constant strain was fixed after the requested load was achieved. Constant strain had the value of $0,662 \%(35,73 \mathrm{~mm})$. The measurement was provided in regular intervals. In the beginning of the experiment the intervals were short (about 5-10 minutes). In the end the intervals were longer (2-4 days).

There was loss of tension of 3,29\% after the first 24 hours. After 28 days the loss was 7,3\% and at the end of the experiment, after 132 days, the loss was $10,5 \%$. However, the experiment was ended early after only 132 days because of lack of space. The measured data are featured in figure 5 .

\section{Nanoindentation of the GFRP bars used}

The GFRP tendon consists of two components - glass fibre and a vinylester matrix. To obtain a good viscoelastic model it is necessary to determine the characteristics of each component. For the determination of the elasticity modulus the nanoindentation method was chosen. This method is based on the testing of material to $\mu \mathrm{m}$ depth and the measuring of force and depth at the same time [7]. This method found that the elasticity modulus of GFRP components is:

$$
\begin{aligned}
& E_{\text {glass }}=52,58 \mathrm{GPa} \\
& E_{\text {matrix }}=5,45 \mathrm{GPa}
\end{aligned}
$$



Figure 4: Creep and shrinkage of the cylinders. 
If using equation:

$$
c_{\text {glass }} \cdot E_{\text {glass }}+c_{\text {matrix }} \cdot E_{\text {matrix }}=E_{\text {GFRP }}
$$

$c_{i}$ is the content of components

$$
E_{G F R P}=39,85 \mathrm{GPa}
$$

This value is very close to the value form table 1 measured in EC. So, the modulus of elasticity of the GFRP tendons used is about $40 \mathrm{GPa}$. Figure 7 shows incisions from the nanoindentation tip on the glass fibre.

\section{Viscoelastic model}

The viscoelastic model is based on the theory of linear viscoelasticity [5]. It is developed in dependence on experimental data. The model consists of two parallel Kelvin chains (figure 8). One is for glass fibre and the second is for the matrix. The first two parameters $\left(\mathrm{E}_{\text {glass }}, \mathrm{E}_{\text {matrix }}\right)$ of the model were determined with the nanoindentation method (chapter 6$)$. The other parameters $\left(\mathrm{E}_{\text {glass, }, \text {, }}\right.$ $\eta_{\text {glass,i, }}, \mathrm{E}_{\text {matrix,i, }}, \eta_{\text {matrix,i }}$ ) were determined with the program GAFPF (Genetic Algorithm Function Parameters Finder), which was written especially for this task. The final approximation of the measured data with the viscoelastic model is featured in figure 9. Basic equations (2)-(4) [5] lead to the scale of the differential equations. These were solved with the Runge-Kutta fourth order method [9]. Relaxation of this model was calculated with eq. (5). The graph of the viscoelastic model outcome compared to measured data against time is shown in figure 9.

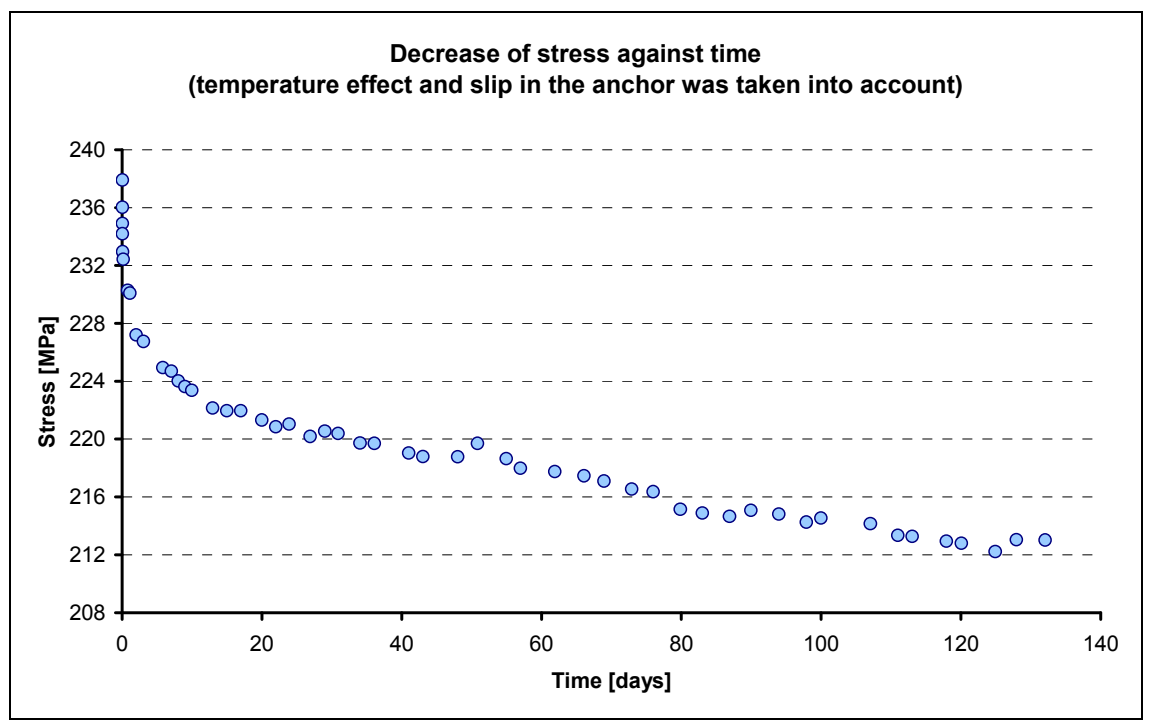

Figure 5: Decrease of stress against time. 


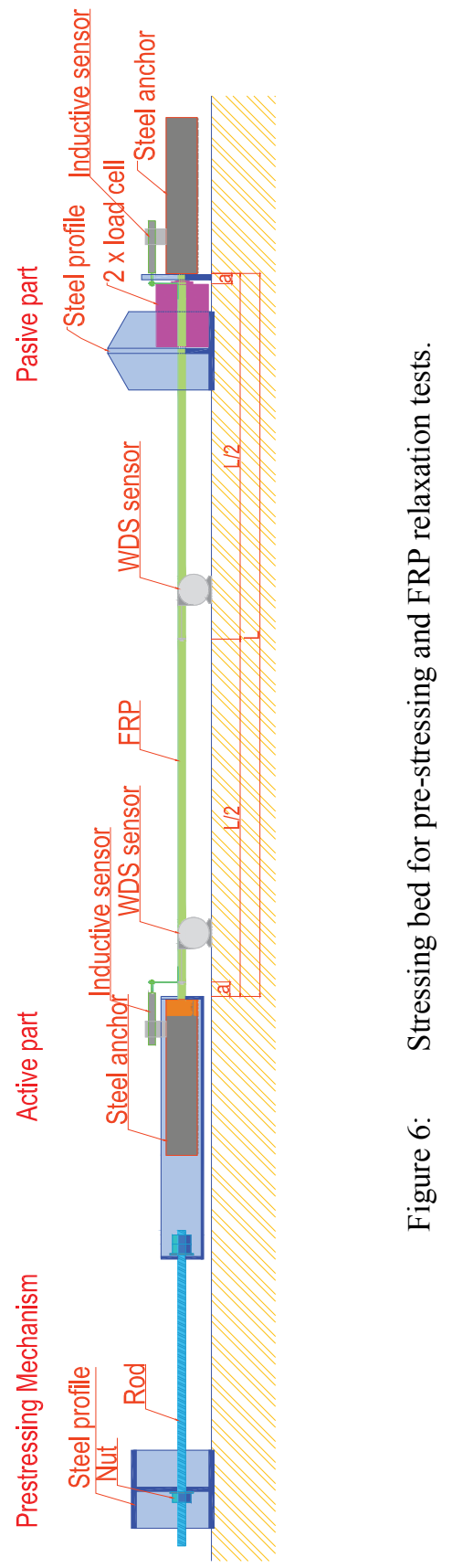






Figure 7: Incisions in glass fibre from the nanoindentation tip.

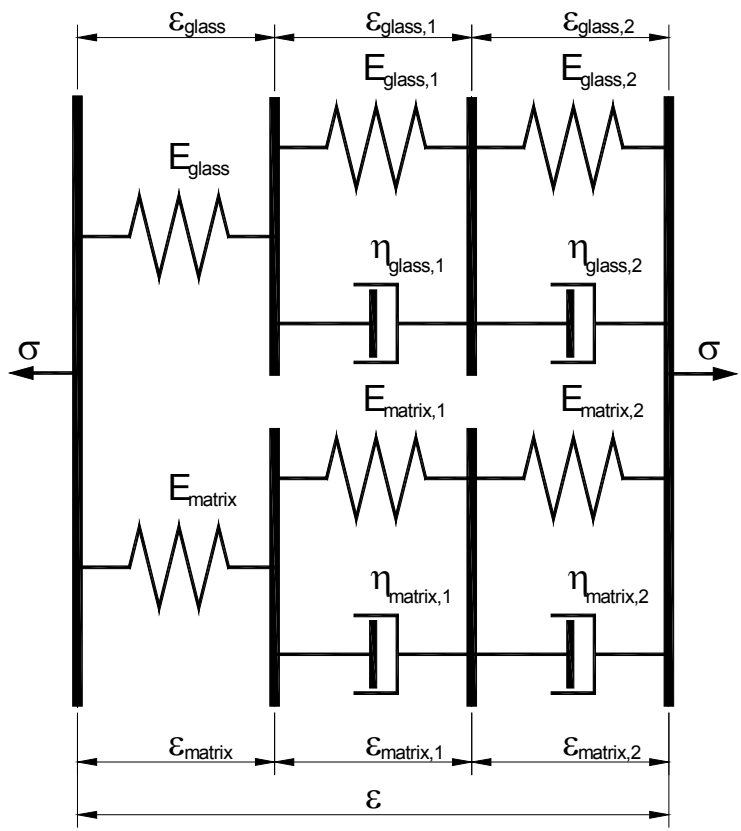

Figure 8: $\quad$ Viscoelastic model. 


$$
\begin{gathered}
\varepsilon(t)=\varepsilon_{\text {glass }}(t)+\varepsilon_{\text {glass }, 1}(t)+\varepsilon_{\text {glass }, 2}(t) \\
\varepsilon(t)=\varepsilon_{\text {matrix }}(t)+\varepsilon_{\text {matrix }, 1}(t)+\varepsilon_{\text {matrix }, 2}(t) \\
\sigma(t)=\sigma_{\text {glass }}(t)+\sigma_{\text {matrix }}(t) \\
t=0 \Rightarrow \varepsilon=\varepsilon_{\text {glass }}=\varepsilon_{\text {matrix }} \\
\varepsilon_{\text {glass }, 1}=0 ; \varepsilon_{\text {glass }, 2}=0 \\
\varepsilon_{\text {matrix }, 1}=0 ; \varepsilon_{\text {matrix }, 2}=0 \\
R_{G F R P}(t)=c_{1} \cdot R_{\text {glass }}(t)+c_{2} \cdot R_{\text {matrix }}(t)
\end{gathered}
$$

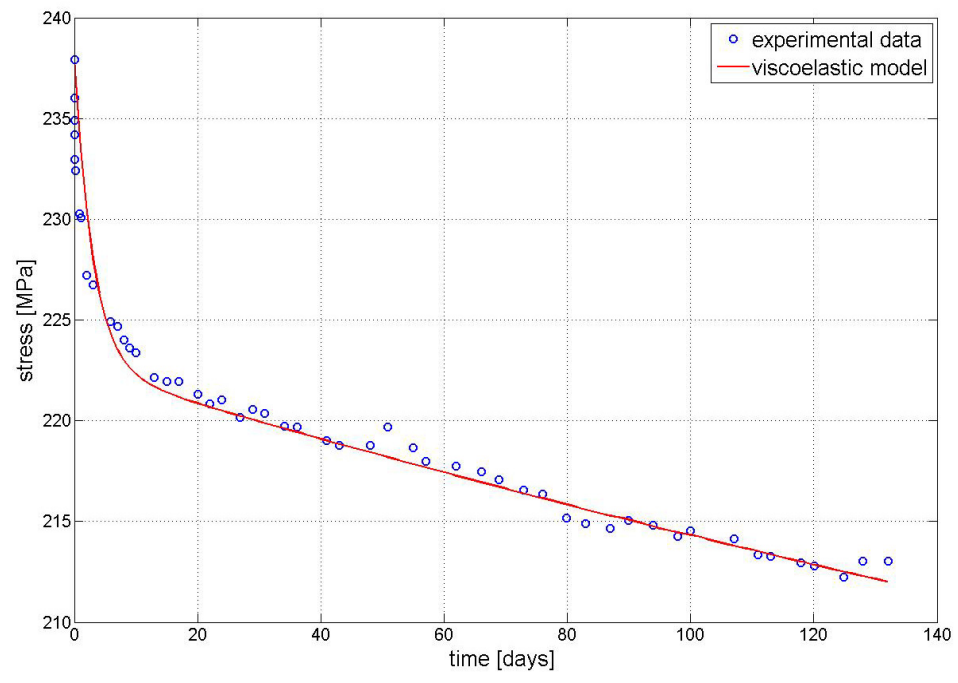

Figure 9: Comparison of experimental data and viscoelastic model.

\section{Conclusion}

The main objective of this paper was determination of the long-term behaviour of GFRP tendons. The following conclusions were deduced from the experimental results:

- The modulus of elasticity presented by the manufacturer was about $20 \%$ lower than that measured in the Experimental Centre.

- The nanoindentation method determined the elasticity modulus of the glass fibres and the matrix:

$$
E_{\text {glass }}=52,58 \mathrm{GPa} \text { and } E_{\text {matrix }}=5,45 \mathrm{GPa} \text {. }
$$


- The GFRP tendon was relaxing very dramatically. The GFRP tendon was pre-stressed to $37 \%$ of its tensile strength. Loss of tension after the first 24 hours was about 3,3\%, after 28 days 7,3\% and at the end of experiment (132 days) it was 10,5\% (figure 7).

- The experiment was ended too early to obtain more significant results. The ideal time for the experiment should be about two years or more for better results.

- The viscoelastic model corresponds to the long-term behaviour during the experiment. However, it is impossible to make some predictions for the longer term because of the short duration of the experiment.

\section{Acknowledgements}

This research has been supported by the Ministry of Industry and Trade under no. 1H-PK2/57, the Ministry of Education of the Czech Republic under no. MSM 6840770031 and an internal grant of the CTU in Prague under no. CTU0801611.

\section{References}

[1] ACI 440.4R-03, Prestressing concrete structures with FRP tendons, American Concrete Institute, Farmington Hills, Mich, 2003

[2] Bažant, Z.P., Jirásek, M., Inelastic analysis of structures

[3] Bittnar, Z., Šejnoha, J., Numerical methods of mechanics 1 (Czech), CTU, Prague, 1992

[4] Dupák, J., Fornůsek, J., Konvalinka, P., Litoš, J., Sovják, R., Measurement and testing line for composite reinforcement in concrete, Utility design request, Prague, 2008

[5] Jirásek, M., Zeman, J., Material deformation and failure (Czech), CTU, Prague, 2006.

[6] Phan-Thien, N., Understanding Viscoelasticity - Basics of Rheology, Springer, Berlin - Heidelberg, Germany, 2002.

[7] Savková, J., Bláhová, O., Nanoindentational measurement of thin layers principles, methods, effects (Slovak), Research Centre - New Technology, University of West Bohemia, 2006

[8] Šejnoha, M., Zeman, J., Micromechanical Analysis of Composites, CTU, Prague, 2002

[9] Vitásek, E., Numerical methods (Czech), SNTL, Prague, 1987

[10] The Mathworks, Inc., MATLAB 2007a Help, The Mathworks, Inc, Natick, Massachusetts, 2007 